\title{
Espécies de Cyperaceae do Centro de Pesquisa e Conservação da Natureza Pró-Mata, município de São Francisco de Paula, RS, Brasil
}

\author{
Pedro Maria de Abreu Ferreira ${ }^{1}$ e Lilian Eggers ${ }^{2,3}$
}

Recebido em 29/05/2006. Aceito em 24/05/2007

\begin{abstract}
RESUMO - (Espécies de Cyperaceae do Centro de Pesquisa e Conservação da Natureza Pró-Mata, município de São Francisco de Paula, RS, Brasil). Foi realizado o levantamento florístico das espécies de Cyperaceae do Centro de Pesquisa e Conservação da Natureza Pró-Mata (CPCN Pró-Mata), Rio Grande do Sul. O local de estudo está situado no município de São Francisco de Paula, na região fisiográfica dos Campos de Cima da Serra. Foram efetuadas cinco expedições de coleta e encontradas 42 espécies, distribuídas em oito gêneros. São apresentadas a lista das espécies, chaves de identificação nos níveis genérico e específico e fotomicrografias em Microscopia Eletrônica de Varredura dos aquênios de cada espécie.
\end{abstract}

Palavras-chave: Cyperaceae, florística, CPCN Pró-Mata, fotomicrografias em MEV, aquênio

ABSTRACT - (Cyperaceae species of the Centro de Proteção e Conservação da Natureza Pró-Mata, São Francisco de Paula municipality, Rio Grande do Sul State, Brazil). A floristic survey of Cyperaceae species at the Centro de Proteção e Conservação da Natureza PróMata (CPCN Pró-Mata), Rio Grande do Sul was performed. The study area is located in São Francisco de Paula municipality, in the physiographic region of the Campos de Cima da Serra. In five collecting expeditions, 42 species were found at the study site, distributed on eight genera. A list of the species, analytical keys for genera and species, as well as scanning photomicrographs of the achenes are presented.

Key words: Cyperaceae, flora, CPCN Pró-Mata, scanning photomicrographs, achene

\section{Introdução}

O Centro de Pesquisas e Conservação da Natureza Pró-Mata (CPCN Pró-Mata) está localizado no município de São Francisco de Paula, Rio Grande do Sul. O local de estudo está inserido na região fisiográfica dos Campos de Cima da Serra, parte integrante do Planalto Meridional. A região é delimitada a leste pelas escarpas de até 900 metros de altura, embasadas pela planície costeira, e a sul pelo talude da Serra Geral. A fisionomia vegetal é composta por um mosaico de zonas de campo e mata, sendo que, originalmente, os campos predominavam em regiões de maior altitude e as matas em baixadas ou ao longo do curso de rios (Rambo 1942). Nos últimos anos, tanto as áreas de campo quanto as de mata vêm sendo alvo de elevada pressão antrópica, com a remoção da vegetação original para a implantação de culturas agrícolas e silviculturais (Boldrini 1997). Essas ações estão acarretando a progressiva descaracterização fisionômica e florística da região.

O CPCN Pró-Mata totaliza uma área de 4.894,41 ha e abrange três regiões fitoecológicas: Campos, Floresta Ombrófila Mista e Floresta Ombrófila Densa. A área apresenta vegetação florestal primária com Floresta Ombrófila Densa em 1.355,64 ha (27,72\% da área total) e Floresta Ombrófila Mista em 1.777,81 ha $(36,36 \%)$. Vegetação florestal secundária ocorre em 972,45 ha $(19,89 \%)$, capoeira em 138,03 ha $(2,82 \%)$ e campos em 147,38 ha $(3,02 \%)$. O restante da área é ocupado por áreas úmidas, corpos d'água, construções, etc. (Baaske \& Tzschupke 2002). Os campos existentes no local são áreas não pastejadas, apresentando estrato herbáceo denso e alto, de aproximadamente $60 \mathrm{~cm}$. A formação campestre do CPCN Pró-Mata tem sido objeto de estudo quanto a

\footnotetext{
Pontifícia Universidade Católica do Rio Grande do Sul, Avenida Ipiranga 6681, 90619-900 Porto Alegre, RS, Brasil

2 Universidade Federal do Rio Grande do Sul, Instituto de Biociências, Departamento de Botânica, Av. Bento Gonçalves 9500, Prédio 43433, 91501-970 Porto Alegre, RS, Brasil

3 Autor para correspondência: lilian.eggers@ufrgs.br
} 
sua caracterização florística e fitossociológica. O levantamento da flora de Poaceae indicou a ocorrência de 68 espécies, destacando-se o número de hibernais (17 espécies) (Caporal \& Eggers 2005). Além deste, foi realizado levantamento fitossociológico do estrato herbáceo na mesma fisionomia campestre, o qual contabilizou 106 espécies, distribuídas em 22 famílias (Eggers et al., dados não publicados). A família Cyperaceae foi representada nesta amostragem por nove espécies. Trabalhos clássicos e mais abrangentes, como o de Rambo (1949), apontaram a ocorrência de 42 espécies da família para a região de Cambará, município relativamente próximo ao local de estudo e pertencente à mesma região fisiográfica.

Cyperaceae é uma família cosmopolita, encontrada principalmente associada às formações vegetais mal drenadas, como brejos, pântanos, charcos e margens de rios e corpos d'água. É composta por mais de 5.000 espécies, distribuídas em 104 gêneros (Goetghebeur 1998). Floras e estudos taxonômicos publicados para a família ainda são escassos. Considerando-se os mais recentes, encontram-se Barros (1960), para o Estado de Santa Catarina; Luceño et al. (1997) para Paraíba e Pernambuco e Martins et al. (1999) para o Parque Estadual Paulo César Vinha, no Espírito Santo. Chave para os gêneros brasileiros da família pode ser encontrada também em Luceño \& Alves (1997).

Em Cyperaceae, a morfologia do aquênio é um caráter de extrema importância na identificação de espécies. A forma, o tamanho, a cor e a ornamentação do fruto são características relevantes e freqüentemente presentes em chaves dicotômicas, nos níveis genérico e específico. Oliveira (1980) analisou a morfologia do aquênio de 31 gêneros de Cyperaceae com o uso de estereomicroscópio, agrupando-os de acordo com a presença ou ausência de estruturas associadas, como estilopódios, cerdas e utrículos.

Por outro lado, estudos utilizando Microscopia Eletrônica de Varredura (MEV) permitem a observação de características gerais de forma e ornamentação do fruto, e também evidenciam aspectos micromorfológicos como a forma e a orientação de células epidérmicas, a forma do lume celular, a presença de corpos silicosos, etc. Estudos com este enfoque têm o objetivo de auxiliar na delimitação de espécies e contribuir para o entendimento da estrutura e função dos diásporos (Lye 2000). Essa ferramenta tem sido utilizada em estudos taxonômicos de gêneros de Cyperaceae (Araújo \& Longhi-Wagner 1997; Guaglianone 1979), assim como em outras famílias, como, por exemplo, Poaceae (Zanin \& Longhi-Wagner 2001; Boechat \& Longhi-Wagner 2003).

O presente trabalho tem como objetivo o levantamento florístico das espécies de Cyperaceae existentes no CPCN Pró-Mata e a apresentação de chaves dicotômicas para sua determinação. Fotomicrografias em MEV dos aquênios são apresentadas, destacando diferenças na morfologia geral do fruto e a caracterização de sua superfície, facilitando a identificação das espécies.

\section{Material e métodos}

O CPCN Pró-Mata está situado entre as coordenadas $29^{\circ} 27^{\prime}-29^{\circ} 35^{\prime} \mathrm{S}$ e $50^{\circ} 08^{\prime}-50^{\circ} 15^{\prime} \mathrm{W}$ (Fig. 1), constituindo-se em uma Área de Conservação pertencente à Pontifícia Universidade Católica do Rio Grande o Sul (PUCRS) desde 1993. O clima da região é do tipo $\mathrm{Cfb}$ úmido a super-úmido, na classificação de Köppen, com índice pluviométrico médio anual de $2.252 \mathrm{~mm}$ temperatura média anual de $14,5^{\circ} \mathrm{C}$ (Bertoletti \& Teixeira 1995). O componente geológico é predominantemente basáltico, como no restante da Região Geomorfológica do Planalto das Araucárias, sendo que o relevo pode se apresentar de ondulado a escarpado (nas altitudes entre 600 e $900 \mathrm{~m}$, com litossolos aflorantes) e de suave ondulado a ondulado (nas altitudes acima de $900 \mathrm{~m}$, com cambissolos brunohúmico-álicos de elevado acúmulo de matéria orgânica no horizonte superficial) (Jüngblut \& Pinto 1997).

As coletas foram realizadas em cinco expedições ao local, abrangendo áreas inalteradas de campos, bordas de mata e mata, além de locais expostos à ação antrópica, como estradas, trilhas e arredores das edificações da sede administrativa. A amostragem foi realizada em janeiro, março e setembro/2004 e fevereiro e abril/2005, procurando abranger as estações de outono, primavera e verão, de acordo os períodos preferenciais de florescimento das espécies. O método de amostragem utilizado foi uma adaptação do Caminhamento, proposto por Filgueiras et al. (1994) para levantamentos florísticos qualitativos. Essa adaptação consistiu basicamente na diminuição das linhas de caminhamento (pois o levantamento enfocou apenas uma família) e na não utilização das etapas de determinação de fisionomias (devido à distribuição predominantemente campestre da família). A campo, foi observada a ocorrência das espécies nas diferentes áreas amostradas (topos de morro e encostas, por exemplo). A bibliografia básica utilizada na 

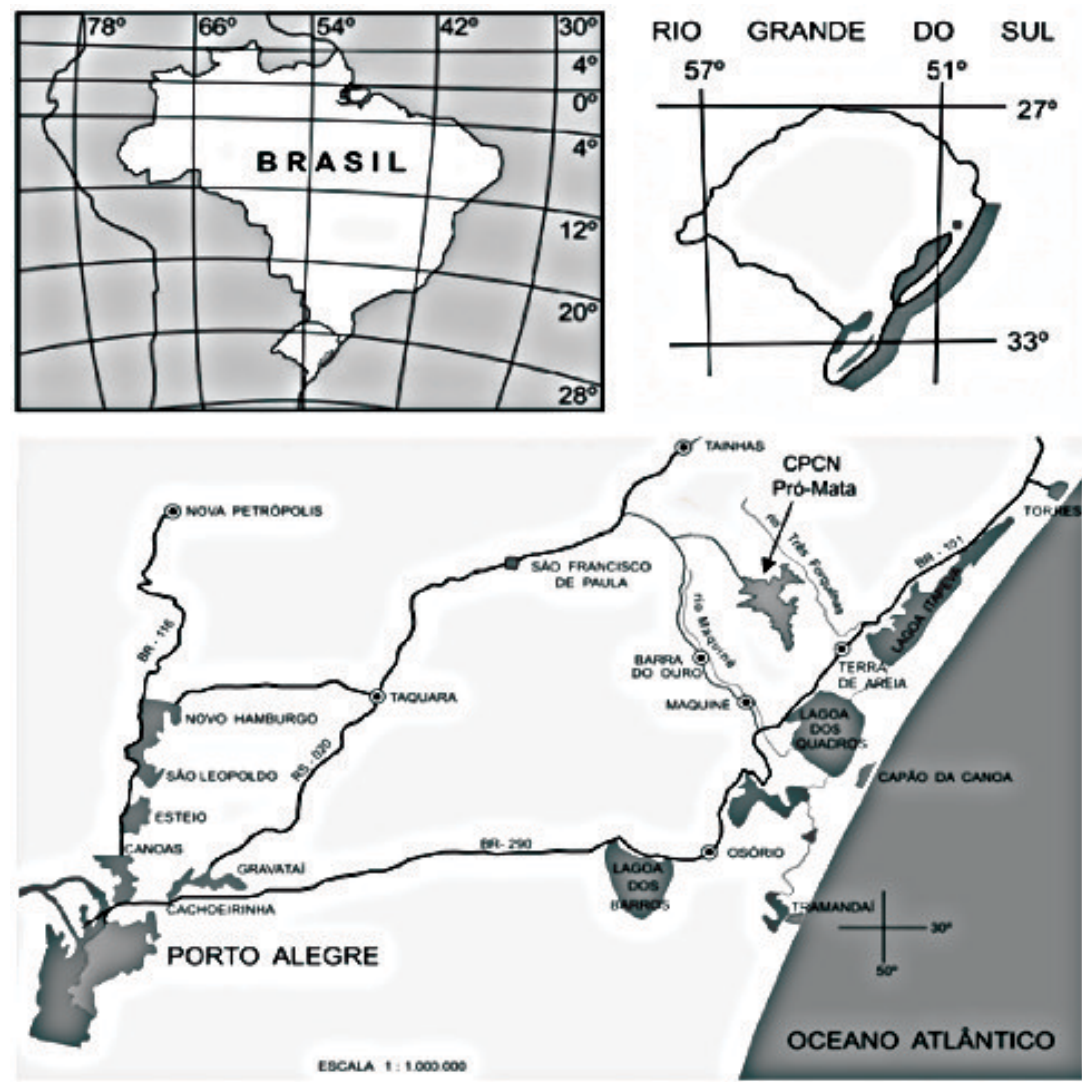

Figura 1. Localização do Centro de Pesquisa e Conservação da Natureza (CPCN) Pró-Mata, RS, Brasil. Modificado de Bertoletti \& Teixeira, 1995.

identificação das espécies foi Adams (1994), Araújo \& Longhi-Wagner (1996), Barros (1960), Guaglianone (1979), Luceño et al. (1997) e Martins et al. (1999). As exsicatas foram incorporadas ao Herbário do Museu de Ciências e Tecnologia da PUCRS (MPUC).

As fotomicrografias dos aquênios foram obtidas no Centro de Microscopia e Micro-Análises (CEMM) da PUCRS, com Microscópio Eletrônico de Varredura Philips modelo XL30. Aquênios em bom estado de conservação de cada espécie foram selecionados a partir do material-testemunho e fixados com fita adesiva dupla-face nos suportes específicos para a microscopia eletrônica (stubs). A preparação das amostras consistiu em desidratação em câmara com sílica e posterior metalização com carbono em câmara de dispersão a vácuo. Os aquênios não sofreram nenhuma espécie de pré-tratamento envolvendo agentes químicos. Em todas as fotomicrografias, os aquênios foram posicionados com o eixo vertical em ângulo reto com a normal e com a base voltada para baixo. Nas fotomicrografias dos detalhes, a superfície selecionada foi a mais representativa e a mais livre de impurezas.
Não são apresentadas as fotomicrografias dos aquênios de Scleria filiculmis Boeck. e de S. panicoides Kunth, devido à má condição de apresentação, decorrente de danos na paredo dos aquênios.

\section{Resultados e discussão}

Foram encontradas 42 espécies de Cyperaceae no CPCN Pró-Mata (Tab. 1), distribuídas em oito gêneros: Bulbostylis Kunth, Carex L., Cyperus L., Eleocharis R. Br., Fimbristylis Vahl, Kyllinga Rottb., Rhynchospora Vahl e Scleria P.J. Bergius. Rhynchospora foi o gênero mais representativo (12 espécies), seguido por Cyperus (oito espécies) e Eleocharis (seis espécies).

Rhynchospora pode ser considerado o gênero mais importante, não somente pelo número de espécies (12 spp.), mas também pela abundância de indivíduos visualizados a campo e sua ocorrência em diferentes ambientes. Nas formações campestres, $R$. polyantha é a espécie mais freqüentemente encontrada, com ocorrência em áreas alagadas e encostas. As áreas 
mais secas, como os topos de morro, são visualmente caracterizadas pela presença de $R$. globosa e $R$. setigera. Em áreas de transição entre campo e mata é típica a ocorrência de $R$. floribunda. Espécies de Rhynchospora, como $R$. brasiliensis, $R$. marisculus, $R$. rugosa e $R$. tenuis apresentam ampla distribuição, sendo comuns em todo o país, enquanto $R$. barrosiana e $R$. polyantha são típicas do sul do Brasil (Barros

Tabela 1. Lista de espécies e respectivo material-testemunho das coleções obtidas no CPCN Pró-Mata, RS, Brasil.

\begin{tabular}{|c|c|}
\hline Espécie & Mat. testemunho \\
\hline Bulbostylis capillaris (L.) C.B. Clarke & Ferreira, P.M.A. 45 \\
\hline $\begin{array}{l}\text { B. distans (Schrad. ex Schult.) Nees ex } \\
\text { Urb. }\end{array}$ & Ferreira, P.M.A. 89 \\
\hline B. juncoides (Vahl) Kük. ex Osten. & Ferreira, P.M.A. 41 \\
\hline B. sphaerocephala (Boeck.) C.B. Clarke & Ferreira, P.M.A. 43 \\
\hline Carex albolutescens Schwein. & Ferreira, P.M.A. 11 \\
\hline C. brasiliensis A. St.-Hil. & Caporal, F.J.M. s.n. \\
\hline C. sororia Kunth & Baaske s.n. \\
\hline Cyperus aggregatus (Willd.) Endl. & Baaske s.n. \\
\hline C. consanguineus Kunth & Ferreira, P.M.A. 85 \\
\hline C. haspan $\mathrm{L}$. & Ferreira, P.M.A. 95 \\
\hline $\begin{array}{l}\text { C. luzulae var. entrerianus (Boeck.) } \\
\text { Barros }\end{array}$ & Ferreira, P.M.A. 55 \\
\hline C. meyenianus Kunth & Ferreira, P.M.A. s.n. \\
\hline C. pohlii (Nees) Steud. & Ferreira, P.M.A. 84 \\
\hline C. reflexus Vahl & Ferreira, P.M.A. 80 \\
\hline C. reflexus var. fraternus (Kunth) Kük. & Ferreira, P.M.A. 77 \\
\hline Eleocharis loefgreniana Boeck. & Ferreira, P.M.A. s.n. \\
\hline E. maculosa (Vahl) Roem \& Schult. & Ferreira, P.M.A. 48 \\
\hline E. minima var. minima Kunth & Ferreira, P.M.A. 71 \\
\hline E. squamigera Svenson & Caporal, F.J.M. s.n. \\
\hline E. subarticulata (Nees) Boeck. & Ferreira, P.M.A. 49 \\
\hline E. viridans Kük. ex Oken & Ferreira, P.M.A. 88 \\
\hline $\begin{array}{l}\text { Fimbristylis autumnalis (L.) Roem. \& } \\
\text { Schult. }\end{array}$ & Ferreira, P.M.A. 98 \\
\hline Kyllinga brevifolia Rottb. & Ferreira, P.M.A. 99 \\
\hline K. odorata Vahl & Ferreira, P.M.A. 18 \\
\hline K. vaginata Lam. & Baaske s.n. \\
\hline Rhynchospora barrosiana Guagl. & Ferreira, P.M.A. 93 \\
\hline R. brasiliensis Boeck. & Ferreira, P.M.A. 90 \\
\hline R. flexuosa C.B. Clarke & Ferreira, P.M.A. 53 \\
\hline R. floribunda Boeck. & Ferreira, P.M.A. 96 \\
\hline R. globosa (Kunth) Roem \& Schult. & Ferreira, P.M.A. 30 \\
\hline R. marisculus Steud. & Ferreira, P.M.A. 94 \\
\hline R. megapotamica (Spreng.) H. Pfeiff. & Caporal, F.J.M. s.n. \\
\hline R. polyantha Steud. & Ferreira, P.M.A. 23 \\
\hline R. rugosa (Vahl) Gale & Ferreira, P.M.A. 39 \\
\hline R. setigera Griseb. & Caporal, F.J.M. s.n. \\
\hline R. tenuis Link & Baaske s.n. \\
\hline R. velutina (Kunth) Boeck. & Ferreira, P.M.A. 74 \\
\hline Scleria ciliata Michx. & Baaske s.n. \\
\hline S. distans Poir. & Ferreira, P.M.A. 75 \\
\hline S. filiculmis Boeck. & Ferreira, P.M.A. 01 \\
\hline S. panicoides Kunth & Betz, H. s.n. \\
\hline S. sellowiana Kunth & Baaske s.n. \\
\hline
\end{tabular}

1960; Guaglianone 1979). Rhynchospora setigera tem ampla distribuição no continente americano, especialmente em ambientes de savana, cerrado e campo rupestre, restringindo sua ocorrência no $\mathrm{CPCN}$ Pró-Mata a locais de solos rasos, mais secos.

Embora Cyperus seja o segundo gênero em riqueza no local de estudo, suas espécies são menos abundantes, o que reflete o caráter megatérmico do gênero, visto que o CPCN Pró-Mata situa-se em região de altitude. Este ambiente é característico para a ocorrência de C. reflexus. Cyperus consanguineus, por outro lado, apresenta coletas somente para o oeste do Brasil meridional e pode ser considerada uma espécie rara nesta e outras localidades. Cyperus aggregatus, C. luzulae var. entrerianus e C. meyenianus são tipicamente espécies ruderais, assim como Fimbristylis autumnalis e as espécies de Kyllinga.

Espécies de Eleocharis são dominantes em baixadas alagadas e margens de aqüíferos, sendo as mais comuns E. viridans e E. minima var. minima. Eleocharis maculosa e E. minima var. minima apresentam ampla distribuição em brejos e campos úmidos de todo o país, enquanto E. viridans é uma espécie comum somente em áreas úmidas do sul do Brasil (Trevisan, comunicação pessoal). O espécime coletado de E. loefgreniana foi referido como nova citação para a flora do Rio Grande do Sul (Trevisan \& Boldrini 2008). No Brasil, a espécie estava citada anteriormente somente para Minas Gerais e São Paulo, representando esta coleta o limite meridional de ocorrência. Embora tenha sido mencionada para a Argentina (Svenson 1939) não há confirmação recente da presença desta espécie neste país (Barros 1947; Guaglianone 1996).

Scleria também ocorre tipicamente em áreas úmidas, com exceção de $S$. panicoides, característica de vegetação florestal e comum na Mata Atlântida (Muniz \& Shepherd 1987). Para a localidade de estudo, esta espécie tem sua ocorrência vinculada à penetração da Floresta Ombrófila Densa na região. Scleria filiculmis é citada para a América do Norte e Central em condições de solos arenoso-argilosos em savanas e em bosques abertos de Pinus (Adams 1994). No Brasil, por outro lado, foi referida somente para uma área úmida bem preservada em Santa Catarina (Barros 1960), em condições de conservação semelhantes às da área aqui estudada. Assim sendo, pode ser considerada uma espécie rara. Scleria sellowiana também ocorre em banhados, no entanto, tem citação restrita ao Brasil meridional, Uruguai e Argentina 
(Barros 1960). Scleria distans destaca-se pela sua frequiência nas formações campestres mais úmidas.

Bulbostylis apresenta espécies que são mais freqüentemente encontradas em afloramentos rochosos (B. hirtella, B. capillaris e B. sphaerocephala) e baixadas úmidas ( $B$. juncoides), enquanto o gênero Carex, tipicamente microtérmico, também se destaca nas baixadas úmidas, em particular pela elevada frequiência de Carex albolutescens.

Não existem estudos específicos da flora de Cyperaceae para a região do Planalto das Araucárias. Rambo (1949) citou a ocorrência de 42 espécies de Cyperaceae para o município de Cambará, contudo não apresentou a lista completa de espécies. Destacou, somente para os banhados da região, a presença de Eleocharis nodulosa (Rottb.) Schult. (= E. montana (Kunth) Roem. \& Schult., Platylepis brasiliensis (Kunth) CBCL. (= Ascolepis brasiliensis (Kunth) Benth. ex C.B. Clarke), Lipocarpha sellowiana Kunth (= Lipocarpha humboldtiana Nees), Cyperus haspan L., Rhynchospora globosa R. et Schult., Fuirena incompleta Nees e F. bahiensis L. et N. (=F. robusta Kunth). No CPCN Pró-Mata, os trabalhos realizados anteriormente tiveram como enfoque o mapeamento de vegetação e o levantamento fitossociológico de uma das formações campestres existentes no local (Baaske \& Tzschupke 2002; Eggers et al., dados não publicados), resultando em um número de espécies amostradas sensivelmente menor, tendo em vista a metodologia empregada para atender a estes objetivos.

Fotografias obtidas em Microscópio Eletrônico de Varredura de 37 aquênios e três utrículos são apresentados nas Fig. 2, 3 e 4. Embora seja de interesse para todos os gêneros neste estudo, a análise das fotomicrografias dos aquênios de Bulbostylis, Eleocharis e Rhynchospora evidenciou características particularmente relevantes para a distinção de espécies próximas. Para as espécies dos demais gêneros, as imagens permitiram uma visualização mais clara da forma e ornamentação do aquênio.

A superfície do fruto, o tipo de inflorescência e o grau de pilosidade da planta constituem os melhores caracteres diagnósticos para Bulbostylis. Nas espécies com inflorescência antelóide, o aquênio levemente tuberculado, com proeminências agudas de Bulbostylis capillaris, difere do aquênio de $B$. hirtella, o qual é fortemente tuberculado, com proeminências arredondadas (Fig. 2A-D). Em plantas com inflorescência monocéfala, as espécies são mais facilmente distintas, tanto por características vegetativas e da inflorescência, quanto pelo aquênio, que é transversalmente rugoso em $B$. juncoides e liso a levemente reticulado em B. sphaerocephala (Fig. 2E-F).

Em Carex, o tipo de inflorescência é útil na distinção entre as espécies. Carex sororia apresenta espiga terminal única, enquanto $C$. albolutescens e C. brasiliensis apresentam um maior número de espigas terminais, distinguindo-se pelo tamanho das mesmas, que são menores na primeira espécie. Os aquênios das três espécies são muito semelhantes, motivo pelo qual optou-se pela confecção da fotomicrografia do utrículo, o qual apresenta colo alado em C. albolutescens (Fig. 2O).

Assim como para as espécies de Carex, em Cyperus, a morfologia e ornamentação dos aquênios não são bons caracteres de diferenciação entre espécies, conforme ressaltado por Lye (2000). Para Cyperus, somente o aquênio de C. haspan pode ser considerado uma exceção, por apresentar-se caracteristicamente obovóide e reticulado (Fig. 3I). Assim sendo, foram utilizadas características da inflorescência (contraída ou com raios evidentes, simples ou composta, tamanho relativo dos raios, etc.), além de caracteres vegetativos para a elaboração da chave dicotômica.

Em Eleocharis, devido à redução das estruturas da inflorescência e das partes vegetativas, a morfologia dos aquênios tem grande importância para a identificação das espécies (Menapace 1990). É interessante destacar o aquênio de E. viridans, único dentre as espécies ocorrentes no CPCN Pró-Mata que não apresenta cerdas hipóginas (Fig. 3G). O padrão da superfície do aquênio é de grande valia na diferenciação entre E. squamigera (Fig. 3E) e E. subarticulata (Fig. 3F), sendo fortemente reticulado e com cristas longitudinais evidentes na primeira e fracamente reticulado e sem estas cristas na segunda. Todavia, outros caracteres como o ápice das glumas e as bainhas foliares são também relevantes no reconhecimento das espécies, tendo em vista que espécimes sem frutos ou com frutos imaturos são freqüentemente coletados.

Características dos aquênios são praticamente irrelevantes na distinção entre as espécies de Kyllinga (Fig. 3I-K). A carena das glumas (espinulosa em K. brevifolia e lisa em K.odorata e K. vaginata) e os rizomas (ausentes em $K$. odorata e presentes em $K$. vaginata) são os caracteres mais evidentes e constantes para diferenciar estas espécies.

Para Rhynchospora, características do aquênio são a base da chave de identificação apresentada 

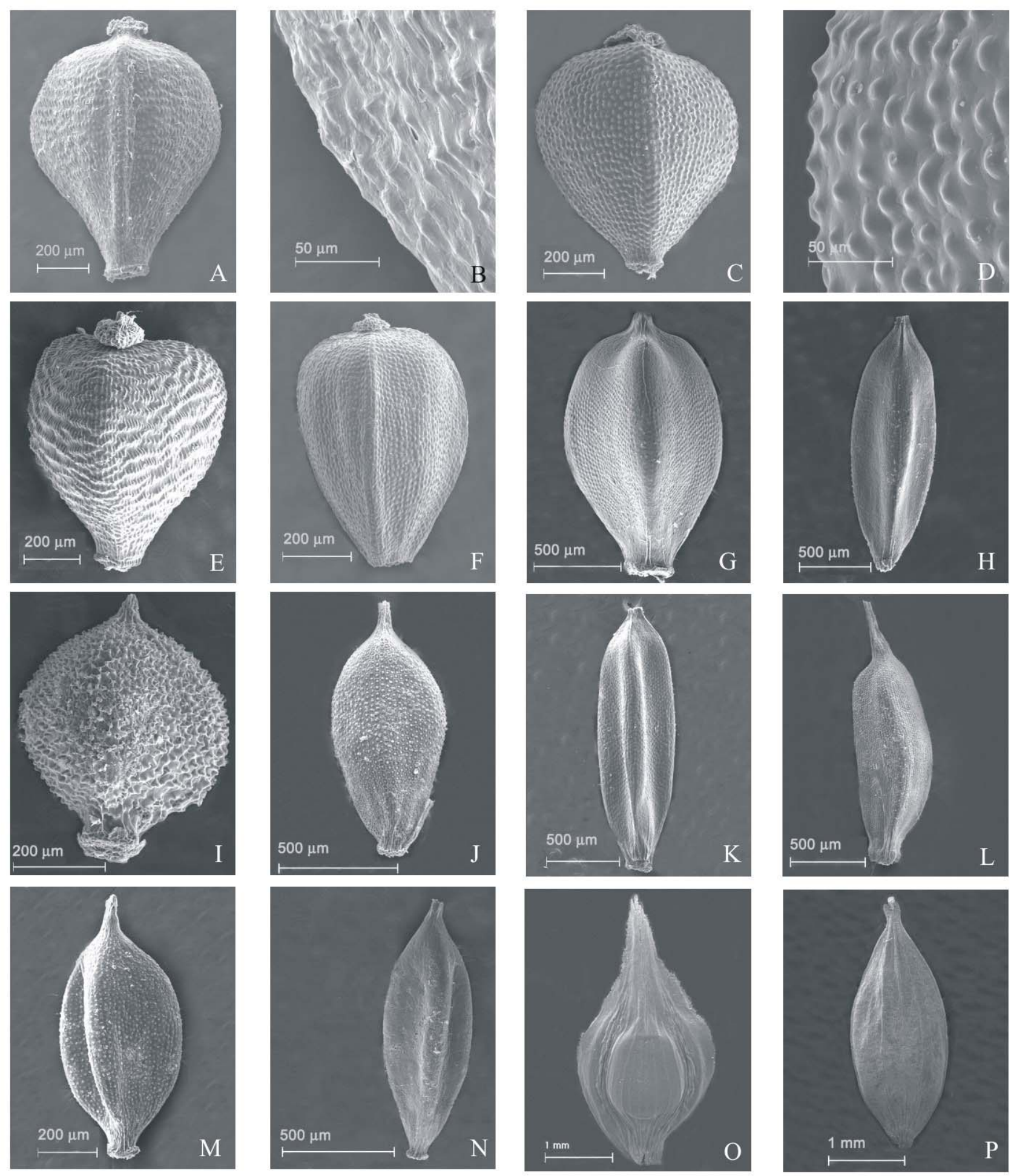

Figura 2. Aquênios (A-N) e utrículos (O-P) das espécies de Cyperaceae no CPCN Pró-Mata, RS, Brasil. A-B. Bulbostylis capillaris (L.) C.B. Clarke. C-D. Bulbostylis distans (Schrad. ex Schult.) Nees ex Urb. E. Bulbostylis juncoides (Vahl) Kük. ex Osten. F. Bulbostylis sphaerocephala (Boeck.) C.B. Clarke. G. Cyperus aggregatus (Willd.) Endl. H. Cyperus consanguineus Kunth. I. Cyperus haspan L. J. Cyperus luzulae var. entrerianus (Boeck.) Barros. K. Cyperus meyenianus Kunth. L. Cyperus pohlii (Nees) Steud. M. Cyperus reflexus Vahl. N. Cyperus reflexus var. fraternus (Kunth) Kük. O. Carex albolutescens Schwein. P. Carex brasiliensis A. St.-Hil. 

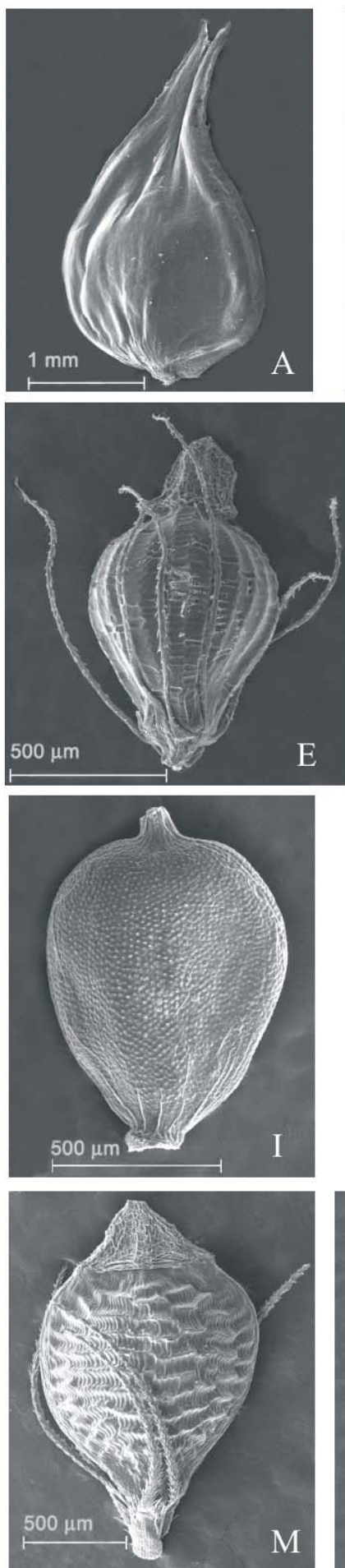
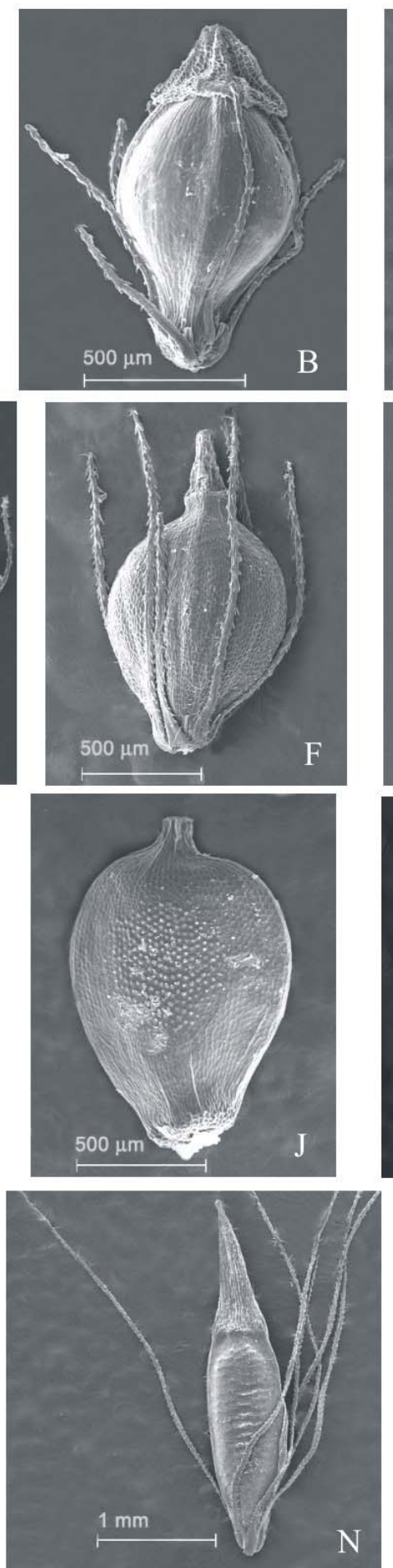
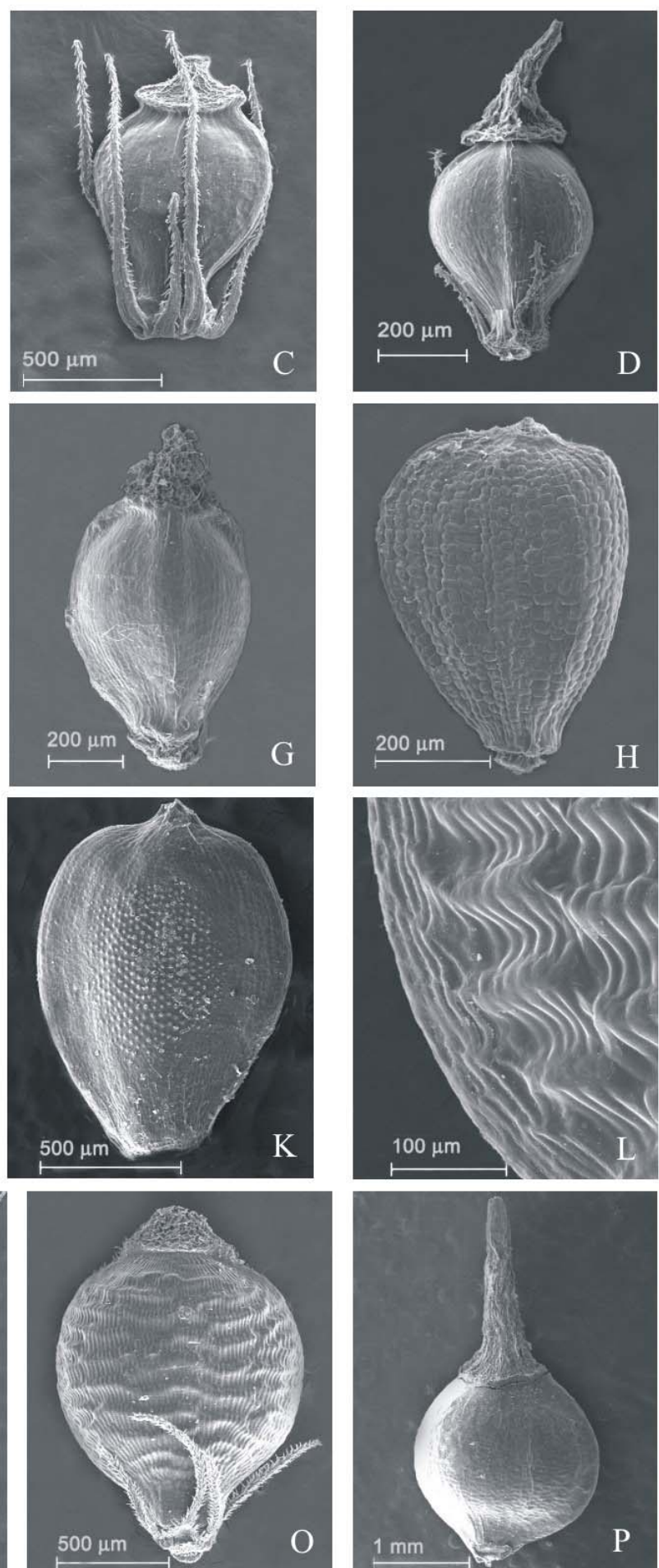

Figura 3. Utrículo (A) e aquênios (B-P) das espécies de Cyperaceae no CPCN Pró-Mata, RS, Brasil. A. Carex sororia Kunth. B. Eleocharis loefgreniana Boeck. C. Eleocharis maculosa (Vahl) Roem. \& Schult. D. Eleocharis minima var. minima Kunth. E. Eleocharis squamigera Svenson. F. Eleocharis subarticulata (Nees) Boeck. G. Eleocharis viridans Kük. ex Oken. H. Fimbristylis autumnalis (L.) Roem. \& Schult. I. Kyllinga brevifolia Rottb. J. Kyllinga odorata Vahl. K. Kyllinga vaginata Lam. L-M. Rhynchospora barrosiana Guagl. N. Rhynchospora brasiliensis Boeck. O. Rhynchospora flexuosa C.B. Clarke. P. Rhynchospora floribunda Boeck. 
por Guaglianone (1979). Espécies próximas como $R$. barrosiana, $R$. marisculus, $R$. polyantha $\mathrm{e}$ $R$. rugosa apresentam distinção quanto à forma do aquênio e à proporção entre o aquênio e o estilopódio. No entanto, a superfície do aquênio é relevante, sendo determinante na identificação de $R$. barrosiana, que apresenta a superfície longitudinalmente estriada, com cristas e sulcos transversais abruptos (Fig. 3L-M), conforme destacado por Guaglianone (1979). Rhynchospora marisculus e $R$. polyantha diferem principalmente pelo aspecto da inflorescência (copiosa e paucirramosa, respectivamente). A inflorescência de $R$. marisculus em campo é bastante distinta da ocorrente em $R$. polyantha. Rhynchospora marisculus apresenta grande número de ramos, os quais são concentrados e densos, especialmente no corimbo terminal. Rhynchospora polyantha tem um menor número de ramos por corimbo, o que fornece um aspecto laxo aos mesmos. Além disto, as espécies apresentam diferenças na forma da base do estilopódio (semilunar em $R$. marisculus e ortogonal em $R$. polyantha) e na forma do aquênio (Fig. 4C-F), visto que a superfície do aquênio é similar, com rugosidade suave quando comparada com $R$. barrosiana. Rhynchospora rugosa (Fig. 4G-H) apresenta superfície do aquênio longitudinalmente estriada, com bandas transversais, de projeção intermediária ao encontrado em $R$. barrosiana e $R$. marisculus ou $R$. polyantha. A principal diferença entre os aquênios de $R$. marisculus $R$. polyantha e $R$. rugosa reside no tamanho do estilopódio relativo ao aquênio, sendo este visivelmente menor do que o aquênio em $R$. rugosa (Fig. 4H) e igual ou maior do que o aquênio em $R$. marisculus (Fig. 4C) e $R$. polyantha (Fig. 4E). O grupo Rhynchospora rugosa apresenta problemas de diferenciação interespecífica que indicam a necessidade de uma revisão taxonômica com base em grande número de material coletado em diversas regiões, aspecto já salientado por Thomas (1994). O estudo da variabilidade morfológica e da descontinuidade de caracteres torna-se essencial para o melhor entendimento da circunscrição das espécies.

Ainda em Rhynchospora, a presença de cerdas hipóginas é determinante na distinção entre espécies.
Estas estão ausentes em $R$. floribunda, $R$. megapotamica, $R$. setigera, $R$. tenuis $\mathrm{e}$ $R$. velutina e presentes em $R$. barrosiana, $R$. brasiliensis, $R$. flexuosa, $R$. globosa, $R$. marisculus, $R$. polyantha e $R$. rugosa. Dentre as espécies amostradas, algumas apresentam características peculiares, de fácil reconhecimento. Rhynchospora flexuosa destaca-se pela presença de cerdas curtas, de extensão menor que a metade do corpo do aquênio (Fig. 3O); R. globosa apresenta cerdas plumosas (Fig. 4A) e $R$. floribunda possui estilopódio longo e estreito (Fig. 3P). Nas espécies de Rhynchospora encontradas no CPCN Pró-Mata, estas características só são observáveis nas espécies apresentadas acima.

As diferenças entre os aquênios de Scleria são bastante evidentes entre as espécies encontradas. Destaca-se a presença de hipogínio formado por tubérculos em S. ciliata e S. sellowiana (Fig. 4L, 4N), além da pilosidade do aquênio que ocorre apenas em S. panicoides. Os padrões de superfície dos aquênios são também taxonomicamente relevantes no gênero. Ocorre superfície fortemente reticulada em S. ciliata (Fig. 4L), fracamente reticulada em S. filiculmis e S. sellowiana (Fig. 4N) e lisa em S. distans (Fig. 4M).

Considerando-se a extensão das áreas campestres, evidencia-se uma riqueza considerável de espécies de Poaceae e Cyperaceae dos campos no CPCN Pró-Mata. Poaceae encontra-se representada por 68 espécies, sendo $25 \%$ de caráter hibernal (Caporal \& Eggers 2005). As condições climáticas de um ambiente mais frio, associada à ausência de pastejo favorecem o desenvolvimento destas plantas. Além de contribuir para o conhecimento da flora local, a listagem das 42 espécies de Cyperaceae destas formações campestres permite constatar a presença de espécies de distribuição restrita ou rara como, por exemplo, Cyperus consanguineus, Eleocharis loefgreniana e Scleria filiculmis. Tais espécies indicam a importância da conservação desta unidade de pesquisa, assim como de estudos para o conhecimento da biodiversidade local.

A seguir são apresentadas chaves de identificação para os gêneros e espécies de ocorrência confirmada no local. 

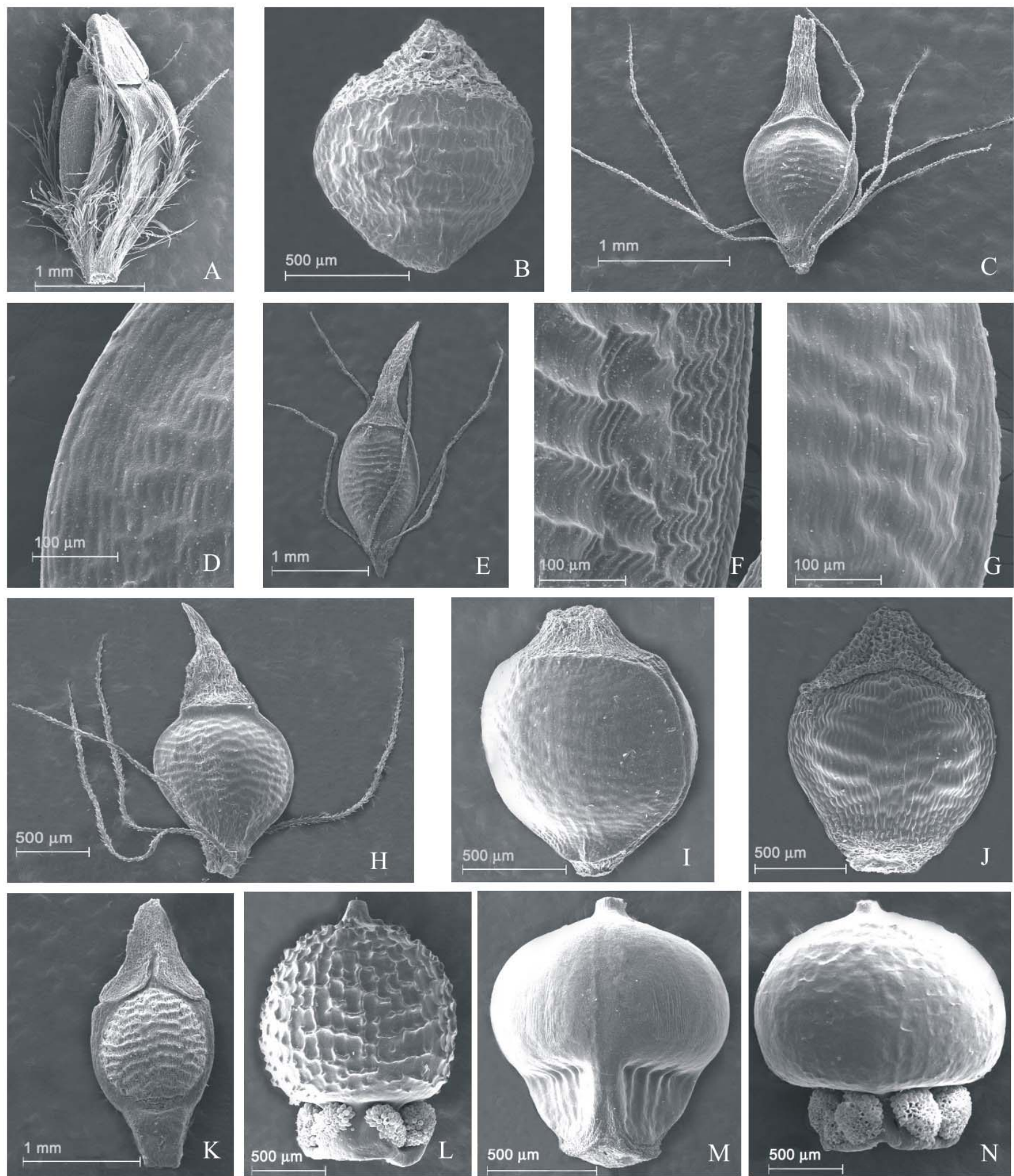

Figura 4. Aquênios das espécies de Cyperaceae no CPCN Pró-Mata, RS, Brasil. A. Rhynchospora globosa (Kunth) Roem. \& Schult. B. Rhynchospora megapotamica (Spreng.) H. Pfeiff. C-D. Rhynchospora marisculus Steud. E-F. Rhynchospora polyantha Steud. G-H. Rhynchospora rugosa (Vahl) Gale. I. Rhynchospora setigera Griseb. J. Rhynchospora tenuis Link. K. Rhynchospora velutina (Kunth) Boeck. L. Scleria ciliata Michx. M. Scleria distans Poir. N. Scleria sellowiana Kunth. 
Chave de identificação para os gêneros

(Quando o gênero está representado somente por uma espécie, esta aparece diretamente na chave)

1. Lâminas foliares ausentes; inflorescência reduzida a uma espigueta terminal, brácteas involucrais ausentes Eleocharis

1. Lâminas foliares presentes; inflorescência com mais de uma espigueta, brácteas involucrais presentes

2. Glumas dísticas

3. Espiguetas 1-2-floras; estilete bífido; aquênios comprimidos lateralmente Kyllinga

3. Espiguetas plurifloras; estilete trífido; aquênios trígonos ou comprimidos dorsiventralmente

Cyperus

2. Glumas espiraladas

4. Aquênio encerrado em utrículo Carex

4. Aquênio livre, na axila da gluma

5. Aquênio globoso, grisáceo ou branco, endurecido; espiguetas bissexuadas, flores unissexuais, pistiladas na base da espigueta e estaminadas no ápice da espiguera Scleria

5. Aquênio obovóide ou oblongo, trígono ou biconvexo, estramíneo, pardo ou castanho, nunca endurecido; flores predominantemente perfeitas

6. Estilete fimbriado; estilopódio caduco (Fig. $3 \mathrm{H}$ ) Fimbristylis autumnalis

6. Estilete nunca fimbriado; estilopódio persistente

7. Ápice da bainha foliar longamente ciliolado; glumas iguais ou subiguais; aquênio trígono; estilopódio globoso Bulbostylis

7. Ápice da bainha foliar glabro; glumas nitidamente desiguais; aquênio biconvexo; estilopódio piramidal . Rhynchospora

Chave de identificação para as espécies

\section{Bulbostylis Kunth}

1. Inflorescência monocéfala

2. Lâminas foliares eretas; inflorescência 3-15 espiguetas; aquênio transversalmente rugoso (Fig. 2E) B. juncoides

2. Lâminas foliares enroladas; inflorescência 20-50 espiguetas; aquênio liso a levemente reticulado (Fig. 2F) B. sphaerocephala

1. Inflorescência antelóide

3. Planta híspida; aquênio fortemente tuberculado (Fig. 2D)

B. hirtella

3. Planta escabrosa apenas nas laterais e nervuras das folhas, raras vezes no escapo; aquênio fracamente tuberculado (Fig. 2B)

B. capillaris

Carex L.

1. Espiga terminal única

C. sororia

1. Espigas terminais 3-7

2. Espigas até $1,4 \mathrm{~cm}$ compr., todas sésseis; colo do utrículo alado (Fig. 2O)

C. albolutescens

2. Espigas 2,5-9,5 cm compr., as basais pediceladas, apicais sésseis; colo do utrículo nunca alado (Fig. 2P) C. brasiliensis

\section{Cyperus L.}

1. Inflorescência capituliforme

2. Inflorescência monocéfala; espiguetas 6-12 mm comp.; aquênios 0,8-1,1 mm compr. C. reflexus

2. Inflorescência composta por 4-8 espigas sésseis; espiguetas 4-5,5 mm compr.; aquênios $1,5-1,9 \mathrm{~mm}$ compr. C. aggregatus 
1. Inflorescência antelóide, com raios evidentes

3. Antela simples

4. Base do escapo claramente trígona; lâmina foliar com septos nodosos; espigueta ovóide, até 5,0 mm compr.

C. consanguineus

4. Base do escapo cilíndrica ou trígona com vértices pouco evidentes; lâmina foliar sem septos nodosos; espigueta lanceolóide, 5,0-15,0 mm compr.

C. reflexus var. fraternus

3. Antela composta

5. Ráquila articulada, caindo com o desprendimento de glumas e aquênios

6. Inflorescência com raios longos maiores que $10,0 \mathrm{~cm}$ compr.

C. pohlii

6. Inflorescência com todos os raios até $8,0 \mathrm{~cm}$ compr.

5. Ráquila não articulada, permanecendo após a queda de glumas e aquênios

7. Lâmina foliar presente; aquênio castanho a negro, elíptico, 1,0-1,2 mm compr., ápice agudo

C. luzulae var. entrerianus

7. Lâmina foliar reduzida a um prolongamento da bainha; aquênio branco, obovóide, 0,6-0,7 mm compr., ápice obtuso

C. haspan

Eleocharis R. Br.

1. Bainha foliar com apêndice hialino rugoso no ápice; estilete bífido; aquênio biconvexo (Fig. 3C)

E. maculosa

1. Bainha foliar sem apêndice hialino rugoso no ápice; estilete trífido; aquênio trígono

2. Aquênios fortemente ou finamente reticulados

3. Glumas superiores adpressas; espiguetas lanceolóides; aquênios fracamente reticulados, sem cristas longitudinais evidentes (Fig. 3F) E. subarticulata

3. Glumas superiores reflexas; espiguetas ovóides a elipsóides; aquênios fortemente reticulados, com cristas longitudinais evidentes (Fig. 3E) E. squamigera

2. Aquênios lisos a levemente culiculados

4. Colmos cilíndricos; glumas superiores com ápice emarginado

E. loefgreniana

4. Colmos quadrangulares; glumas superiores com ápice obtuso ou agudo

5. Plantas até 12,0 cm alt.; espiguetas 2,5-4,5 mm compr., 3-8 flores; glumas superiores dísticas ou subdísticas; colmos 0,1-0,2 mm larg.; cerdas hipóginas presentes (Fig. 3D)

E. minima var. minima

5. Plantas com mais de 15,0 cm alt.; espiguetas 6,0-13,0 mm compr., 30-60 flores; glumas superiores espiraladas; colmos 0,3-0,7 mm larg.; cerdas hipóginas ausentes (Fig. 3G)

E. viridans

Kyllinga Rottb.

1. Gluma de carena espinulosa; inflorescência monostáquia, esverdeada; estame 1

K. brevifolia

1. Gluma de carena lisa; inflorescência mono a tristáquia, esbranquiçada; estames 2 ou 3

2. Rizomas ausentes; estames 2; inflorescência geralmente tristáquia

K. odorata

2. Rizomas presentes; estames 3; inflorescência monostáquia

K. vaginata

Rhynchospora Vahl

1. Inflorescência monocéfala

2. Inflorescência esbranquiçada; glumas membranosas; cerdas hipóginas ausentes (Fig. 4I) ......R. setigera

2. Inflorescência parda; glumas endurecidas; cerdas hipóginas presentes, plumosas (Fig. 4A)

1. Inflorescência corimbosa ou paniculada

R. globosa

3. Cerdas hipóginas ausentes

4. Lâminas foliares 10,0-12,0 mm larg.; aquênio com estilopódio no mínimo 5,0 mm compr. 
(Fig. 3-P); plantas esciófilas, de borda de mata..... R. floribunda

4. Lâminas foliares 1,0-4,0 mm larg.; aquênio com estilopódio até 3,2 mm compr.; plantas heliófilas

5. Inflorescência paniculada; aquênio com estilopódio 1,3-1,5 mm compr. R. megapotamica

5. Inflorescência corimbosa

6. Aquênio com estilopódio no mínimo 3,0 mm compr. (Fig. 4K) R. velutina

6. Aquênio com estilopódio 1,3-1,7 mm compr. (Fig. 4J). R. tenuis

3. Cerdas hipóginas presentes

7. Folhas capilares; inflorescência 1-2 corimbos, cerdas hipóginas iguais ou menores que a metade do corpo do aquênio (Fig. 3O)

R. flexuosa

7. Folhas planas, nunca capilares; inflorescência multicorimbosa, cerdas hipóginas evidentemente maiores que a metade do corpo do aquênio

8. Aquênio linear-oblongo (Fig. 3N); aquênio com estilopódio 3,2 mm compr. R. brasiliensis

8. Aquênio obovóide ou elíptico, nunca linear; aquênio com estilopódio até $3,0 \mathrm{~mm}$ compr.

9. Aquênio com sulcos transversais, com cristas abruptas bem definidas; estilopódio de até $1 / 3$ de seu comprimento (Fig. 3L-M). R. barrosiana

9. Aquênio com sulcos transversais, sem cristas abruptas; com estilopódio pouco menor ou maior que seu comprimento

10. Base do estilopódio semilunar (Fig. 4C); inflorescência copiosa, 5-7 corimbos laterais dispostos nos três quartos finais do escapo R. marisculus

10. Base do estilopódio reta; inflorescência paucirramosa, até 4 corimbos laterais dispostos apenas no quarto final do escapo

11. Planta cespitosa; estilopódio 0,6-0,7 mm compr., aquênio de base mais estreita que o ápice (Fig. 4H)

R. rugosa

11. Planta de rizomas curtos; estilopódio 1,1-1,4 mm compr., aquênio de base tão larga quanto o ápice (Fig. 4E)

R. polyantha

Scleria P.J. Bergius

1. Inflorescência paniculada; aquênio híspido nas saliências da ornamentação

S. panicoides

1. Inflorescência fasciculada; aquênio glabro

2. Espiguetas dispostas em fascículos ao longo do escapo floral S. distans

2. Espiguetas dispostas em fascículos terminais

3. Glumas glabras; aquênio liso; hipogínio ausente S. filiculmis

3. Glumas ciliadas ao menos na carena; aquênio ornamentado; hipogínio presente, composto por 3 pares de tubérculos

4. Escapo pubescente; aquênio fracamente reticulado (Fig. 4N)

4. Escapo glabro; aquênio fortemente reticulado (Fig. 4L)

S. sellowiana S. ciliata

\section{Referências bibliográficas}

Adams, C.D. 1994. Cyperaceae. Pp. 402-404; 423-485. In: G. Davidse; S.M. Sousa \& A.O. Chater (eds.). Flora Mesoamericana. México, Universidad Autonoma Mexico. v. 6. Alismataceae a Cyperaceae.

Araújo, A.C. \& Longhi-Wagner, H.M. 1996. Levantamento taxonômico de Cyperus L. subg. Anosporum (Nees) Clarke (Cyperaceae-Cyperae) no Rio Grande do Sul, Brasil. Acta Botanica Brasilica 10: 153-192.

Araújo, A.C. \& Longhi-Wagner, H.M. 1997. Anatomia foliar e micromorfologia da superfície do fruto na taxonomia de Cyperus L. (Cyperaceae). Iheringia, Sér. Bot. 48 : 103-120.
Baaske, R. \& Tzschupke, W. 2002. Vegetationskartierung in der südbrasilianischen Serra Geral mit Hilfe von IRFarbluftbildern. Photogrammetrie, Fernerkundung, Geoinformationen 3: 161-170.

Barros, M. 1947. Cyperaceae. Pp. 1-243. In: H. Descole. Genera et Species Plantarum Argentinarum. Tomo 4, parte 1 .

Barros, M. 1960. Las Ciperaceas del Estado de Santa Catalina. Sellowia 12: 181-450.

Bertoletti, J.J. \& Teixeira, M.B. 1995. Centro de Pesquisas e Conservação da Natureza Pró-Mata. Termo de Referência. Divulgações do Museu de Ciências e Tecnologia, UBEA/PUCRS 2: 1-47. 
Boldrini, I.I. 1997. Campos do Rio Grande do Sul: Caracterização fisionômica e problemática ocupacional. Boletim do Instituto de Biociências/UFRGS 2: 1-39.

Boechat, S.C. \& Longhi-Wagner, H.M. 2003. Análise do fruto em espécies de Eragrostis Wolf (Poaceae). Iheringia, Sér. Bot. 58:131-166.

Caporal, F.J.M. \& Eggers, L. 2005. Poaceae na área do Centro de Pesquisas e Conservação da Natureza Pró-Mata, São Francisco de Paula, Rio Grande do Sul, Brasil. Iheringia 60: $141-150$.

Filgueiras, T.S.; Brochado, A.L.; Nogueira, P.E.; Guala II, G.F. 1994. Caminhamento - Um método expedito para levantamentos florísticos qualitativos. Cadernos de Geociências 12: 39-43.

Goetghebeur P. 1998. Cyperaceae. Pp. 141-190. In: Kubitzki, K. (ed.) The families and genera of vascular plants: IV. Flowering plants - monocotyledons. Berlin, Springer

Guaglianone, E.R. 1979. Sobre Rhynchospora rugosa (Vahl) Gale (Cyperaceae) y algunas especies afines. Darwiniana 22: 255-311.

Guaglianone, E.R. 1996. Cyperaceae (Excepto Amphiscirpus, Isolepis, Schoenoplectus y Scleria). In: F.O. Zuloaga \& O. Morrone (eds.). Catálogo de las plantas vasculares de la República Argentina. Monographs in Systematic Botany from the Missouri Botanical Garden 60: 128-197.

Jüngblut, M. \& Pinto, L.F.S. 1997. Levantamento de solos do Centro de Pesquisa e Conservação da Natureza PróMata. Divulgação do Museu de Ciências e Tecnologia, UBEA/PUCRS 3: 29-94.

Luceño, M. \& Alves, M.V. 1997 Clave de los géneros de ciperáceas de Brasil y novedades taxonómicas y corológicas en la familia. Candollea 52: 185-197.

Luceño, M.; Alves, M.V. \& Mendes, A.P. 1997. Catálogo florístico y claves de identificación de las ciperáceas de los estados de Paraíba y Pernambuco (Nordeste do Brasil). Anales Jardín Botánico Madrid 55: 67-100.
Lye, K.A. 2000. Achene structure and function of structure in Cyperaceae. Pp. 615-628. In: K.L. Wilson \& D.A. Morrison. Monocots: Systematics and Evolution. Melbourne, CSIRO.

Martins, M.L.L.; Carvalho-Okano, R.M. \& Luceño, M. 1999. Cyperaceae do Parque Estadual Paulo César Vinha, Guarapari, Espírito Santo, Brasil. Acta Botanica Brasilica 13: $187-222$.

Menapace, F.J. 1990. A preliminary micromorphological analysis of Eleocharis (Cyperaceae) achenes for systematic potential. Canadian Journal of Botany 69: 1533-1541.

Muniz, C. \& Shepherd, G.J. 1987. O gênero Scleria (Cyperaceae) no Estado de São Paulo. Revista Brasileira de Botânica 10: 63-94.

Oliveira, E.C. 1980. Cyperaceae Juss. Morfologia dos aquênios de gêneros ocorrentes no Brasil. Rodriguésia 55: $327-405$.

Rambo, S.J. 1942. A fisionomia do Rio Grande do Sul: ensaio de monografia natural. Porto Alegre, Oficina Gráfica da Imprensa Oficial.

Rambo, S.J. 1949. A flora de Cambará. Anais Botânicos do Herbário Barbosa Rodrigues 1: 111-135.

Svenson, H.K. 1939. Monographic Studies in the Genus Eleocharis V. Rhodora 41: 1-19, 43-77, 90-110.

Thomas, W.W. 1994. Rhynchospora. Pp. 404-423. In: G. Davidse; S.M. Sousa \& A.O. Chater (eds.). Flora Mesoamericana. México, Universidad Autonoma Mexico. v. 6. Alismataceae a Cyperaceae.

Trevisan, R. \& Boldrini, I.I. 2008. O gênero Eleocharis R.Br. (Cyperaceae) no Rio Grande do Sul, Brasil. Revista Brasileira de Botânica 6: 7-67.

Zanin, A. \& Longhi-Wagner, H.M. 2001. Micromorfologia da superfície do fruto em espécies de Andropogon L. (Poaceae) ocorrentes no Brasil. Insula 30: 35-46. 